\title{
As dimensões da informação pública: transparência, acesso e comunicação
}

\author{
The dimensions of public information: \\ transparency, access and communication
}

Carmem Lúcia BATISTA'

\section{RE S U M O}

As reivindicações ocorridas em vários países, dentre eles o Brasil, por direito de acesso à informação pública nos chamam a atenção para um fator que extrapola o âmbito jurídico da questão. Dessa forma, o presente artigo tem por objetivo discutir questões subjacentes ao direito de acesso à informação pública, buscando refletir sobre as concepções de transparência e acesso. Para fundamentar teoricamente as questões propostas, são utilizadas concepções de vários autores, dentre eles Norberto Bobbio. Também são utilizados resultados de pesquisas empíricas, em âmbitos nacional e internacional, que investigaram a facilidade, ou não, de acesso à informação pública. Este estudo conclui que ao se tratar de direito à informação pública, há fatores subjacentes imbricados ao acesso e à transparência, como as dimensões física, intelectual e comunicacional.

Palavras-chave: Acesso à informação. Comunicação. Informação pública.

\section{A B S T R A C T}

The claims made in several countries, including Brazil, for right of access to public information makes us aware of a factor that goes beyond the legal scope of the issue. Therefore, this article aims to discuss issues related to the right of access to public information by trying to reflect on the concepts of transparency and access. To theoretically justify the proposed questions, several authors' concepts are used, including Norberto Bobbio. We also used the results of national and international empirical research, which investigates the facility or lack of access to public information. This article concludes that there are latent factors involved in access and transparency when dealing with right to public information, such as the physical, intellectual and communicative dimensions.

Keywords: Access to information. Communication. Public information.

\section{NTRODUÇÃ O}

As reivindicações ocorridas em vários países, dentre eles o Brasil, por direito de acesso à informação pública nos chamam a atenção para um fator que extrapola o âmbito jurídico da questão. Além da legalidade e da legitimidade, o direito de acesso à informação pública também traz implicações práticas sobre o que se entende por informação pública e qual tipo de acesso se está pleiteando.

Diante de tais indagações, este artigo tem por objetivo discutir questões subjacentes ao direito de acesso à informação pública, partindo do conceito de informação pública para refletir sobre as concepções de transparência e acesso. Dessa forma, a priori, é

\footnotetext{
1 Secretaria da Fazenda do Estado de São Paulo, Núcleo de Documentação e Informação. Av. Rangel Pestana, 300, 17 andar, 01017-911, São Paulo, SP, Brasil. E-mail: <carlubatista@gmail.com>.

Recebido em 16/9/2010 e aceito para publicação em 24/1 1/2010.
} 
necessário abordar o conceito de informação pública a fim de que os fatores subjacentes da definição possam apresentar alguns indícios para a discussão da temática aqui proposta.

A questão da informação pública foi recentemente abordada na pesquisa de Batista $(2010$, p.40), na qual é construído um conceito para o termo:

[...] informação pública é um bem público, tangível ou intangível, com forma de expressão gráfica, sonora e/ou iconográfica, que consiste num patrimônio cultural de uso comum da sociedade e de propriedade das entidades/instituições públicas da administração centralizada, das autarquias e das fundações públicas. A informação pública pode ser produzida pela administração pública ou, simplesmente, estar em poder dela, sem o status de sigilo para que esteja disponível ao interesse público/coletivo da sociedade. Quando acessível à sociedade, a informação pública tem o poder de afetar elementos do ambiente, reconfigurando a estrutura social.

Essa definição considera que a dimensão pública da informação produzida pelo Estado é apresentada em oposição a privado e a segredo. Nesse sentido, a atual luta por direito à informação, além de pleitear o acesso público, é também uma reivindicação contra o segredo de Estado, nos casos em que a informação não tem o status de sigilo. No entanto, ao considerar que o acesso social à informação pública pode reconfigurar a estrutura da sociedade, a questão do acesso não pressupõe apenas o acesso físico, mas também a transparência e a compreensão do "homem comum" sobre o que é produzido e publicado pelo Estado. Nessa perspectiva, há alguns fatores imbricados no processo de acesso, em sentido stricto, à informação pública.

Se, por um lado, recursos tecnológicos, como a internet, proporcionam maior rapidez e facilidade na busca por informação pública, por outro, não são esses recursos que garantem a transparência e a facilidade de acesso. Assim, há que se considerar uma realidade que supere a questão da legalidade de disponibilidade da informação. Afora os obstáculos legais, há também os não legais. Dessa forma, tanto transparência quanto acesso envolvem problemas que o direito de acesso, ou seja, a permissão concedida por lei ao cidadão para acessar a informação pública, não é capaz de resolver. Embora a lei seja condição necessária e importante para conferir legalidade ao ato de acessar os documentos públicos, é também insuficiente para decidir problemas de ordem mais prática.

Vários autores tratam a questão da transparência e do acesso à informação pública, seja para abordar questões relacionadas à disponibilidade de acesso (Britto, 1992; Organização para a Cooperação de Desenvolvimento Econômico, 2001 ; Islam, 2003; Bellver, 2007; Arten, 2008), seja para abordar a necessidade de compreensão da informação publicada (Seclaender, 1991; Jardim, 1999a, 2004, 2008; Bovens, 2002; Villanueva, 2002; Fundo Monetário Internacional, 2007; Lopes, 2007; Limberger, 2007; Griselda et al., 2008; Access Info Europe, 2009). É possível perceber que, ao se tratar da transparência e do acesso à informação pública, estão sendo considerados sentidos distintos.

Conforme Jardim (1999b), a noção de acesso à informação se relaciona a um direito, mas também a dispositivos políticos, culturais, materiais e intelectuais que garantem o exercício efetivo desse direito. De acordo com o autor, o acesso jurídico à informação pode garantir ao usuário o acesso físico, mas não se consolida sem o acesso intelectual à informação. Para que haja transparência informacional, segundo o autor, é necessário um território para o qual confluam práticas informacionais do Estado e da sociedade. A "opacidade informacional" do Estado sinaliza, ao contrário, um hiato entre ele e a sociedade, configurando-se como processo e produto das características de geração e uso da informação pelo cidadão (Jardim, 2008, p.89).

Nesse sentido, os problemas de transparência e acesso à informação pública estão relacionados à:

- Dimensão física: há dificuldade em acessar fisicamente o documento público.

Essa dificuldade se dá, em parte, porque: a) o sigilo se tornou regra, não exceção (essa situação é mais frequente em caso de documentos antigos) (Jardim, 1999a, Weichert, [200-]; Bastos, 2007); b) há falta de organização da informação pública, tanto em meio eletrônico como em meio impresso (Costa; Fraiz, 1989; Fonseca, 1996; Jardim, 1999a, 1999b, 2004, 2008); c) há excesso e escassez de informação (Kakabadse et al., 2003; Silva, 2005; Ramos Júnior; Rover, 2007; Coleman et al., 2008; Access Info Europe, 2009; Morgeson III; Mithas, 2009). 
- Dimensão intelectual: a transparência pressupõe compreensão, que viabiliza o acesso intelectual com possibilidade de apropriação simbólica. A linguagem utilizada em documentos públicos e o formato de publicação da informação pública, principalmente o conteúdo publicado em diários oficiais, não são compreensíveis à maior parte da sociedade (Habermas, 1984; Seclaender, 1991; Bobbio, 2000, 2004a; Villanueva, 2002; Limberger, 2007; Lopes, 2007).

- Dimensão comunicacional: há dificuldade em se tomar conhecimento da informação pública devido à ineficácia do fluxo comunicacional entre o Estado e a sociedade e, também, pelo fluxo informacional, marcado pelo excesso de informação (organizada ou não) (Bobbio, 2000, 2004b; Bastos, 2007).

\section{Dimensão física}

Além da dificuldade de acesso, o problema da organização da informação pública implica mais duas consequências que parecem antagônicas, mas que não são autoexcludentes: excesso de informação e escassez de informação. Por um lado, a antinomia da dificuldade de acesso físico é a pluralidade de opções. $\bigcirc$ excesso de informação desorganizada, tanto no meio eletrônico como no impresso, inviabiliza o acesso físico. Por outro lado, a falta de informação disponível ou organizada também é empecilho para seu acesso físico.

Segundo Jardim (1999b; 2004; 2008), há precariedade dos registros arquivísticos e computacionais e produção de volumosos estoques informacionais insuficientemente gerenciados. Paralelamente à implantação do governo eletrônico, não são observadas mudanças significativas nos padrões de produção, processamento e uso dos estoques informacionais públicos. Segundo o autor, na administração pública brasileira há a coexistência de diferentes princípios de estruturação: patrimonial, burocrática e "nichos de modernização", configurando-se, nesse quadro, uma situação em que: a) o Estado não controla a si mesmo, o que se expressa na fragilidade da maior parte de suas estruturas e recursos informacionais e na ausência de políticas de informação; b) a sociedade, consequentemente não controla o Estado, devido às escassas possibilidades de acesso à informação pública.

No campo empírico, também há algumas constatações. Ao pesquisar o acesso aos arquivos públicos municipais, Fonseca (1996) identificou alguns proble- mas quanto à organização dos arquivos: a) situação precária dos arquivos públicos, que não têm autoridade necessária para estabelecer rotinas e normas de gestão de documentos; b) espaço físico inadequado para recolhimento e organização dos documentos; c) quadro funcional inadequado para tratamento técnico dos documentos.

Um exemplo de que a organização não é um problema que se encerra no arranjo físico da informação é apresentado pela Access Info Europe (2009), uma organização internacional de direitos humanos que promove o direito de acesso à informação na Europa e no mundo. Essa organização pesquisou como é distribuído o dinheiro dos fundos de auxílio que recebem doações de contribuintes de países desenvolvidos para combater a fome e a pobreza de países em desenvolvimento. Em outubro de 2009, essa organização publicou um relatório sobre uma pesquisa que monitorou o acesso e a disponibilidade de informação em websites de agências responsáveis pela tramitação de doações que cinco países desenvolvidos (Canadá, França, Noruega, Espanha e Reino Unido) enviavam a cinco países em desenvolvimento (Afeganistão, Kosovo, Moçambique, Peru e Serra Leoa). A pesquisa identificou:

a) Baixo nível de acesso e de disponibilidade. Havia pouca informação, ou informação incompleta, sobre orçamentos, contratos, consultas e mecanismos de anticorrupção. Os sites eram estruturados de acordo com a lógica das agências, não para as necessidades dos usuários.

b) Indisponibilidade de detalhes. Não era possível, ao público, fazer conexões entre os orçamentos e os contratos e as atividades em andamento.

c) Não havia correlação positiva entre as seções dedicadas a países ou portais em websites da agência de auxílio e as altas pontuações nos indicadores de monitoramento.

d) Dificuldade de acesso à informação. As informações estavam "profundamente enterradas" em sites governamentais ou em base de dados e a organização da informação não era estruturada para usuários não treinados. $\bigcirc$ acesso também foi dificultado pela complexa terminologia em alguns documentos ou excesso de simplificação em outros.

e) Pouca informação, no site das agências de auxílio, sobre mecanismos de anticorrupção ou medidas tomadas pelas agências para promover a integridade dos fundos de auxílio. 


\section{Dimensão intelectual}

Desde o século XVIII, na obra Dos delitos e das penas, com explícita influência das idéias de Rousseau, Beccaria (2001, p.22) iá demonstrava preocupação com a dificuldade de compreensão dos textos legislativos pelo "homem comum":

Enquanto o texto das leis não for um livro familiar, uma espécie de catecismo, enquanto forem escritas numa língua morta e ignorada do povo, e enquanto forem solenemente conservadas como misteriosos oráculos, o cidadão que não puder julgar por si mesmo as conseqüências que devem ter os seus próprios atos sobre a sua liberdade e sobre os seus bens ficará na dependência de um pequeno número de homens depositários e intérpretes das leis.

A dificuldade em acessar cognitivamente a informação pública ocorre, em parte, por características que são implícitas à organização da estrutura da administração pública. Por operar no âmbito das leis, a administração pública obedece a princípios de racionalidade - impessoalidade e formalidade -, o que resulta numa linguagem legislativa de difícil compreensão. Na técnica legislativa, por meio da qual as leis e as normas são produzidas, há uma complexidade de raciocínio: a norma é pensada em linguagem comum, depois traduzida para a linguagem jurídico-administrativa, para depois ser interpretada para a linguagem comum. Contudo, essa última parte do processo nem sempre ocorre e, muitas vezes, a linguagem complexa das leis e das normas é somada a um formato de publicação pouco acessível.

De acordo com Bobbio (2000; 2004a), a comunicação do Estado tem sido insuficiente à concretização do governo democrático. Como consequência, cabe à sociedade um sofisticado instrumental analítico para compreender plenamente a conduta das autoridades. Partindo de uma avaliação semelhante, Habermas (1984) conclui que a liberdade de informação está dependendo da realização de um processo permanente de tradução das informações oriundas do Estado para termos inteligíveis ao "homem comum". Nesse sentido, completa Seclaender (1991, p. 152), "o direito de ser informado não pode deixar de implicar também um direito à explicação, sob pena de perder sua própria razão de ser".

Assim, o cidadão tem diante de si um complexo universo de normas jurídicas no âmbito administrativo, mas não sabe o que fazer com elas, como elas podem beneficiá-lo ou como ele pode ser afetado por elas. De acordo com Villanueva (2002) e Limberger (2007), o fato de essas normas serem publicadas no Diário Oficial não significa que a população se encontre informada, pois poucas pessoas compram regularmente ou acessam pela Internet tal publicação, fonte de informação pouco atrativa e estranha à grande maioria das pessoas, que tem dificuldade para traduzir a linguagem normativa em linguagem coloquial e para correlacionar os alcances, limites e exceções das normas.

No entanto, há formas de contornar parte dessa situação. Para serem oficialmente publicados, os textos legais, em sua maioria, são acompanhados de exposições de motivos ou justificativas que os explicam: quem propõe a norma, por que a propõe e em que contexto ela se insere. Essas exposições de motivos ou justificativas não são sigilosas e não devem, necessariamente, obedecer à linguagem legislativa.

Outra forma de atenuar a dificuldade de compreensão do Diário Oficial foi encontrada pela Comunidade Europeia. Preocupada em tornar, em termos intelectuais, a informação pública mais acessível, a Comunidade Europeia desenvolveu um site <http:// eur-lex.europa.eu/pt/index.htm $>$ em que reorganiza as informações publicadas no Jornal Oficial da União Europeia. Paralelamente, é mantido o acesso ao formato oficial e padronizado do jornal.

A necessidade de clareza nas informações produzidas pelo Estado também é uma preocupação de organismos internacionais. Em 2007, o Fundo Monetário Internacional (2007) publicou o Manual de Transparência Fiscal, que dispõe sobre os princípios e as práticas para a disponibilidade de informação pública na área fiscal, de forma a facilitar a análise das políticas e promover a prestação de contas. De acordo com esse manual, a transparência fiscal beneficia: a) os cidadãos, ao fornecer-lhes as informações de que necessitam para responsabilizar o governo por suas decisões de políticas; b) os governos, que terão acesso facilitado aos mercados internacionais de capitais; c) a sociedade civil, que poderá exercer uma vigilância mais intensa sobre o Estado; d) os mercados internacionais, ao incentivar os governos à adoção de políticas econômicas corretas e consolidar a estabilidade financeira. 
Ao publicar as melhores práticas de transparência orçamentária, a Organisation for Economic Co-operation and Development (2002) defende a divulgação irrestrita, sistemática e tempestiva de todas as informações fiscais e apresenta uma série de melhores práticas referentes aos principais relatórios orçamentários.

\section{Dimensão comunicacional}

Na dimensão comunicacional, estão envolvidos fluxos informacionais e comunicacionais - facilitados pela tecnologia - que tanto podem favorecer como dificultar a relação Estado-sociedade. Essa dimensão se configura em dificuldade de acesso e transparência da informação pública, que implica o controle dos fluxos que podem abalar a participação social e, como consequência, a democracia.

Segundo o Instituto Federal de Acesso à Informação Pública (México, 2008), órgão mexicano, a transparência pode ser definida por três elementos: abertura da informação por parte do governo, comunicação ou conhecimento por parte dos cidadãos e prestação de contas ou justificação, aos cidadãos, das decisões adotadas pelo governo.

Quanto à abertura da informação pública, uma lei de acesso resolve a questão; em relação à comunicação e à prestação de contas, a questão é mais complexa porque envolve a preparação do cidadão para realmente tomar conhecimento dos negócios públicos e, também, o estabelecimento de um fluxo comunicacional eficiente por parte do Estado. Sobre esse último elemento, Cordero Sanz (2007) afirma que há duas formas de orientar a natureza dos documentos públicos: informar ou narrar compromissos e ações relacionadas à administração pública, em que pode predominar um enfoque descritivo nem sempre detalhado ou estruturado; informar sobre as políticas, ações, processos, resultados obtidos e impactos medidos num período determinado, cuja finalidade seja a prestação de contas às partes interessadas. Na primeira forma de orientação, há o risco de não possibilitar a avaliação do comportamento e o grau de coerência das estratégias e políticas da administração pública e, também, há o risco de que a informação transmitida não permita comparações ou avaliações (temporal, geográfica, de resultados por atividade etc.). Na segunda forma de orientação, os canais de informação entendem que o objetivo principal é transmitir informação mais relevante de forma transparente e de modo adequado para que possa servir para tomada de decisões às partes interessadas.

Dessa forma, a questão da transparência e do acesso ao volume de informação produzida e já disponibilizada pelo Estado é uma situação que envolve o controle do fluxo, por parte do Estado ou da sociedade. Em relação a essa realidade, Bastos (2007) e Bobbio (2000; 2004b) fazem algumas considerações. De acordo com Bastos (2007), há uma desigualdade de controle entre Estado e sociedade. Essa disparidade antinômica aumenta significativamente à medida que a informática permite o desenvolvimento de mecanismos e programas que ampliam os poderes de armazenamento de informações sigilosas, confidenciais ou reservadas pelo Estado, sem que aumentem os poderes do indivíduo de controlar as ações abusivas do Estado.

Conforme Bobbio (2000; 2004b), o Estado é proprietário de grandes memorizadores artificiais, o que sinaliza uma tendência oposta à que deu vida à democracia como ideal do poder visível: a orientação não é mais rumo ao máximo controle do poder por parte dos cidadãos, mas ao máximo controle dos cidadãos por parte de quem detém o poder. Dessa forma, se é verdade que num Estado democrático a sociedade "vê" o poder estatal mais que num Estado autocrático, também é verdadeiro que por meio da tecnologia o Estado democrático pode "ver" o público bem melhor do que em tempos passados. Dessa forma, os avanços tecnológicos podem representar novos modos para o Estado exercer o que Bobbio (2000) denomina de "poder invisível", uma capacidade de ver sem ser visto.

Assim, no acesso da informação pública estão implicados conceitos que vão além do fator jurídico, de legalidade e de legitimidade, que a reivindicação pelo direito à informação pública pode, aparentemente, supor. Devem ser discutidas, junto ao pleito, as condições para que a transparência e o acesso, em todas suas acepções, estejam imbricados às dimensões físicas, intelectuais e comunicacionais da informação pública. Somente ao considerar essas dimensões será possível a apropriação social da informação pública para a constituição de relações concretas entre o Estado e a sociedade. 


\section{REFERÊNCIAS}

ACCESS INFO EUROPE. Not available! Not accessible!: aid transparency monitoring report. Madrid: Access Info Europe, 2009.

ARTEN, F.A.C. Portais de comunicação pública online como propulsora de alternativas democráticas. Pensamento Plural, v.2, n.2, p.63-69, 2008.

BASTOS, A.W. O habeas data e a proteção da privacidade individual: recuperação histórica da evolução conceitual e constitucional no Brasil. 2007. Disponível em: <http://www.buscalegis. ufsc.br/revistas/index.php/buscalegis/article/viewFile/15977/ 15541 > . Acesso em: 13 jan. 2010.

BATISTA, C.L. Informação pública: entre o acesso e a apropriação social. 2010. 202f. Dissertação (Mestrado em Ciência da Informação) - Escola de Comunicações e Artes, Universidade de São Paulo, São Paulo, 2010.

BECCARIA, C. Dos delitos e das penas. Bauru: Edipro, 2001.

BELLVER, A. Reforma en materia de transparencia: segunda generación de cambio institucional. Revista del CLAD: Reforma e Democracia, n. 38, p. 1-27, 2007.

BOBBIO, N. O futuro da democracia. 9. ed. São Paulo: Paz e Terra, 2000.

BOBBIO, N. A era dos direitos. Rio de Janeiro: Elsevier, 2004a.

$\mathrm{BOBBIO}, \mathrm{N}$. Estado, governo, sociedade: para uma teoria geral da políitica. 11. ed. Rio de Janeiro: Paz e Terra, 2004b.

BOVENS, M. Information rights: citizenship in the Information Society. Journal of Political Philosophy, v. 10, n.3, p.317-341, 2002.

BRITTO, C.A. Distinção entre "controle social do poder" e "participação popular". Revista de Direito Administrativo, n.189, p.114-122, 1992.

COLEMAN, R. et al. Public life and the internet: if you build a better website, will citizens become engaged? New Media \& Society, v. 10, n.2, p. 179-201, 2008.

CORDERO SANZ, C. Derecho de acceso a la información y transparencia: herramientas necesarias para la democracia en una sociedad abierta. In: SEMINARIO INTERNACIONAL COMPLUTENSE, Madrid, 2007. Anais... Madrid: Universidad Complutense de Madrid, 2007. p.55-67.

COSTA, C.M.L.; FRAIZ, P.M.V. Acesso à informação nos arquivos brasileiros. Estudos Históricos, v.2, n.3, p.63-76, 1989.

FONSECA, M.O.K. Direito à informação: acesso aos arquivos públicos municipais. 1996. Dissertação (Mestrado em Ciência da Informação) - Escola de Comunicação, Universidade Federal do Rio de Janeiro, Rio de Janeiro, 1996.

FUNDO MONETÁRIO INTERNACIONAL. Manual de transparência fiscal. FMI, 2007. Disponível em: <https://www.imf.org/ external/np/fad/trans/por/manualp.pdf>. Acesso em: 25 nov. 2009.
GRISELDA, A.; MARÍA, O.L.; FLORENCIA, S.M. Políticas estatales de acceso a la información y su incidencia de cultura política. Revista Documentación, v.2, n.8, p.40-48, 2008. Disponible en: $<$ http://documents.scribd.com/docs/1 vi5of5y8sq7c676 0+9c.pdf>. Acceso: 22 abr. 2009.

HABERMAS, J. Mudança estrutural da esfera pública: investigações quanto a uma categoria da sociedade burguesa. Rio de Janeiro: Tempo Brasileiro, 1984.

ISLAM, R. Do more transparent governments govern better? Washington: World Bank, 2003. (Policy Reserch Working Paper, n. 3077).

JARDIM, J.M. Transparência e opacidade do Estado no Brasil: usos e desusos da informação governamental. Niterói: Editora UFF, 1999a.

JARDIM, J.M. O acesso à informação arquivística no Brasil: problemas de acessibilidade e disseminação. In: MESA REDONDA NACIONAL DE ARQUIVOS, Rio de Janeiro, 1999b. Disponível em: <http://www.conarq.arquivonacional.gov.br/Media/ publicacoes $/ \mathrm{mesa} /$ o_acesso_informao_arquivstica_no_brasil. $\mathrm{pdf}>$. Acesso em: $11 \mathrm{dez} .200 \overline{9}$.

JARDIM, J.M. A construção do e-gov no Brasil: configurações político-institucionais. In: ENCONTRO NACIONAL DE CIÊNCIA DA INFORMAÇÃO, 5., 2004, Salvador. Anais eletrônicos... Salvador: UFBA, 2004. Disponível em: <http://www.cinform. ufba.br/v_anais/artigos/josemariajardim.html>. Acesso em: 15 dez. 2009

JARDIM, J.M. A face oculta do Leviatã: gestão da informação e transparência administrativa. Revista do Serviço Público, v.59, n. 1, p.81-92, 2008.

KAKABADSE, A.; KAKABADSE, N.K.; KOUZMIN, A. Reinventing the democratic governance project through information technology? A growing agenda for debate. Public Administration Review, v.63, n. 1, p.44-60, 2003.

LIMBERGER, T. Transparência administrativa e novas tecnologias: o dever de publicidade, o direito de ser informado e o princípio democrático. Revista de Direito Administrativo, n.245, p.248-263, 2007.

LOPES, C.A. Acesso à informação pública para melhoria da qualidade dos gastos públicos: literatura, evidências empíricas e o caso brasileiro. Cadernos de Finanças Públicas, n.8, p.5-40, 2007.

MÉXICO. Instituto Federal de Acceso a la Información Pública. Los criterios y resoluciones del IFAI. 2008. Disponible en: <http:// www.ifai.org. $\mathrm{mx} /$ descargar.php? $r=/ p d f / c i u d a d a n o s / s i t i o s$ _de_interes/estudio/\&a=Criterios\%20y\%20resoluciones $\% 20$ del\%20IFAl.pdf>. Acceso: 15 enero 2010.

MORGESON III, F.V.; MITHAS, S. Does e-government measure up to e-business?: comparing end user perceptions of U.S. Federal government and e-business websites. Public Administration Review, v.69, n.4, p.740-752, 2009. 
ORGANIZAÇÃO PARA A COOPERAÇÃO E DESENVOLVIMENTO ECONÔMICO. Cidadãos como parceiros: informação, consulta e participação pública na formulação de políticas. Paris: OCDE, 2001.

ORGANISATION FOR ECONOMIC CO-OPERATION AND DEVELOPMENT. Best practices for budget transparency. OCDE, 2002. Available from: <http://www.oecd.org/dataoecd/33/13/ 1905258.pdf>. Cited: 4 Nov. 2009.

RAMOS JÚNIOR, H.S.; ROVER, A.J. Democracia eletrônica na sociedade da informação. In: CONGRESSO NACIONAL DO CONSELHO NACIONAL DE PESQUISA DE PÓS-GRADUAÇÃO EM DIREITO, 16., Belo Horizonte, 2007. Anais eletrônicos... 2007. Disponível em: <http://conpedi.org/manaus/arquivos/anais/bh/aires_jose_rover.pdf>. Acesso em: 29 out. 2009.
SECLAENDER, A.C.L. O direito de ser informado: base do paradigma moderno do direito de informação. Revista de Direito Público, v.25, n.99, p.147-159, 1991.

SILVA, S.P. Graus de participação democrática no uso da internet pelos governos das capitais brasileiras. Opinião Pública, v. 11 , n.2, p.450-468, 2005.

VILLANUEVA, E. Derecho comparado de la información. 2. ed. Ciudad del México: Universidad lberoamericana, 2002.

WEICHERT, M.A. O direito à verdade e os arquivos sigilosos. [200-]. Disponível em: <http://sejarealistapecaoimpossivel. blogspot.com/2008/1 1/arquivos-secretos-e-direito-verddade. $\mathrm{html}>$. Acesso em: 14 jan. 2010.
231

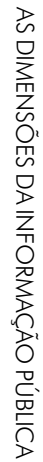


